NBER WORKING PAPER SERIES

\title{
EMPLOYMENT, UNEMPLOYMENT, AND PROBLEM DRINKING
}

John Mullahy

Jody L. Sindelar

Working Paper No. 5123

\author{
NATIONAL BUREAU OF ECONOMIC RESEARCH \\ 1050 Massachusetts Avenue \\ Cambridge, MA 02138 \\ May 1995
}

This research has been supported in part by Grant 1R01AA08394 from the U.S. National Institute on Alcoholism and Alcohol Abuse at Yale University; Mullahy's research was also supported in part by a University Fellows grant from Resources for the Future. Earlier versions of this paper were presented at the CUNY Graduate Center, Johns Hopkins University, Rutgers University, the 1993 Econometric Society Summer Meetings, the 1995 AEA meetings, and the Conference on Research in Health Economics at the University of Chicago. Particular thanks are owed to the participants in these seminars as well as to Don Kenkel, Will Manning, Jeff Miron, John Strauss, and Joe Terza for helpful comments, suggestions, and discussions. Mark Blazejowski, Amy Kiuchi, and Zhiewe Ma provided expert programming and research assistance. This paper is part of NBER's research program in Health Economics. Any opinions expressed are those of the authors and not those of the National Bureau of Economic Research.

(0) 1995 by John Mullahy and Jody L. Sindelar. All rights reserved. Short sections of text, not to exceed two paragraphs, may be quoted without explicit permission provided that full credit, including $\odot$ notice, is given to the source. 
NBER Working Paper \#5123

May 1995

\title{
EMPLOYMENT, UNEMPLOYMENT,
} AND PROBLEM DRINKING

\begin{abstract}
The misuse of alcoholic beverages ("problem drinking") has been demonstrated to result in enormous economic costs; most of these costs have been shown to be reduced productivity in the labor market. The purpose of this paper is to present sound structural estimates of the relationship between various measures of problem drinking and of employment and unemployment. The sample of approximately 15,000 observations is drawn from the 1988 Alcohol Survey of the National Health Interview Survey, the first dataset that enables nationallyrepresentative estimates of alcohol abuse and dependence consistent with generally accepted medical criteria. The structural estimates of the effects of problem drinking on employment and labor market participation are obtained using methods proposed by Amemiya and by Heckman and MaCurdy.

For our sample of males ages 25 to 59 , we find that using the instrumental variable approach suggests that the negative impact of problem drinking on employment is even greater than that estimated using the OLS approach. Interestingly, the IV estimates on the samples of females change the sign from a positive impact of problem drinking on employment to a negative impact. Thus although the conclusions drawn from raw data comparisons and OLS regressions differ by gender, the IV estimates are very similar for men and women. For women, the unobserved heterogeneity masks the negative impact of problem drinking on employment when using OLS estimation methods.
\end{abstract}

John Mullahy

Department of Economics

Trinity College

300 Summit Street

Hartford, CT 06106

and NBER
Jody L. Sindelar

Yale School of Public Health

60 College Street

PO Box 208034

New Haven, CT 06520-208034 and NBER 


\section{EMPLOYMENT, UNEMPLOYMENT, AND PROBLEM DRINKING ${ }^{1}$ \\ John Mullahy'2 and Jody L. Sindelar \\ "...the higher wages they receive makes them neither happier nor richer, since they only drink more and work less..."}

Benjamin Franklin

Paris, 1776-1785

\section{INTRODUCTION}

Enormous economic costs have been associated historically and continue currently to be associated with alcohol abuse, or 'problem drinking'. This association has been a motivation for alcohol-related public policies in the U.S. and world-wide. Lost productivity is considered to be the largest component of the costs of problem drinking ${ }^{4}$. Most of the extant empirical literature has substantiated the commonly held view that 'problem drinking' is associated with lower earnings, lower employment rates and greater unemployment. However, we reopen the issue of problem drinking and employment for several reasons. First, several recent studies suggest that alcohol consumption may be beneficial for productivity (Berger and Leigh, 1988: and Cook, 1992), at least at moderate levels of consumption (French and Zarkin, forthcoming) in samples of workers. Second, most

1. This research has been supported in part by Grant 1R01AA08394 from the U.S. National Institute on Alcoholism and Alcohol Abuse to Yale University; Mullahy's research was also supported in part by a University Fellows grant from Resources for the Future. Earlier versions of this paper were presented at the CUNY Graduate Center, Johns Hopkins University, Rutgers University, the 1993 Econometric Society summer Meetings, the 1995 AEA meetings, and the Conference on Research in Health Economics at the University of Chicago. Particular thanks are owed to the participants in these seminars as well as to Don Kenkel, Will Manning, Jeff Miron, John strauss, and Joe Terza for helpful comments, suggestions, and discussions. Mark Blazejowski, Amy Kiuchi, and zhiewe Ma provided expert programming and research assistance.

2. Trinity College and NBER.

3. Yale University and NBER.

4. See Rice et al. 1990. 
of the studies have used reduced form or hybrid analysis and have not determined the structural relationships between problem drinking and productivity. Further, in a previous study we found that reduced employment may be the greatest negative effect on labor market success, some studies have focused on workers only. The purpose of this paper is to present some sound structural estimates of the relationship between various measures of problem drinking and measures of employment and labor market participation. These relationships can be used to assess the potential merits of alcohol policies.

The relatively small but rapidly growing body of economics literature has focused on alcohol as a causal factor in employment problems. In contrast, the sociology and alcohol research literature have taken the opposite perspective, asking to what degree unemployment causes alcohol problems. However, combining the two perspectives suggests that there may be either reverse causality or an omitted factor driving both phenomena. These latter possibilities have not typically been combined in empirical studies to determine the structural linkages, Kenkel and Ribar, 1994, provide the exception.

In this paper we explore the extent to which problem drinking causes unemployment by instrumenting for problem drinking ${ }^{5}$ in models of employment, unemployment and labor force participation. We use data from the 1988 Alcohol Survey of the National Health Interview Survey (NHIS) that allows us to develop what we consider to be credible instruments for problem drinking. This paper extends our

\footnotetext{
5. We use the term 'problem drinking' to refer generally to any of several types of alcohol disorders, alcohol problems, or heavy drinking. These represent a set of separate but related indicators and for expository ease we refer to them as a group through the use of the term problem drinking. The definitions of and the differences among the alcohol-related problems and disorders are discussed in more detail in the next section. Note that in previous research we confined our analysis specifically to a diagnosed alcohol abuse and dependence. In this paper, however we expand our consideration of a broader spectrum of alcohol indicators.
} 
line of research on alcohol and labor market outcomes and also on gender differences in several ways. We use a new data set, focus specifically on employment outcomes, use alternative measures of problem drinking, and account explicitly for the effects of unobserved heterogeneity by using an instrumental variable approach in estimation. This work complements to some degree the work of Kenkel and Ribar, 1994.

Our focus in this paper is primarily on measures of problem drinking; it is problem drinking not alcohol consumption per se that we believe will result in employment problems. However, in addition to measures of problem drinking, we use a measure of aggregate alcohol consumption (total ethanol) in order to make comparisons with findings of other studies which have used similar measures of alcohol consumption. We examine the extent to which problem drinking, and consumption of alcohol, increase unemployment and reduce employment after controlling to the degree possible for unobserved heterogeneity.

The rest of the paper is organized as follows. Section II provides some needed background. Section III provides a conceptual framework for the inter-relationships between problem drinking and employment. The data set and our sample are discussed in section IV. Section $V$ presents the econometric strategy that we pursue. Results are discussed in section VI while section VII concludes.

\section{BACKGROUND}

This section provides background information on problem drinking and covers literature on the interlinkages between employment problems and problem drinking. First, we review some aspects of the 
epidemiology of problem drinking and alcohol consumption. We discuss distinctions among alcohol use and misuse and diagnoses of alcohol related disorders. Then we consider reasons why alcohol problems might cause employment problems and, conversely, why employment problems could cause problem drinking, considering also the possibilities of unobserved factors causing both. Then empirical studies relating problem drinking to unemployment are briefly reviewed.

\section{A. Problem Drinking and Employment}

i. Definitions of alcohol use and abuse

In discussing the 'problem drinking'/employment relationship, we use the term 'problem drinking' to encompass several different conceptual and empirical measures. We explore empirically the extent to which different measures of problem drinking are detrimental to success in employment. We first distinguish between problem drinking and alcohol consumption per se. The measures of problem drinking that we use include heavy drinking and the diagnosis of an alcohol-related disorder. We are concerned with problem drinking because this sort of drinking is most likely to be associated with employment problems. We contend that there is little reason to expect that light or moderate consumption would result in employment problems. However, in our analysis, we also include a measure of consumption of ethanol to explore the possibility of some employment/alcohol consumption relationships and to compare to other literature that has used levels of consumption in studies. Consumption measures typically quantify 
alcohol consumption per time period, and are often expressed in units of "pure alcohol" or ethanol. Consumption of alcohol could also be measured in several different ways: number of drinks per time period, typical drinks per day, maximum drinks at a time, or drinking in specific situations, e.g., in harmful situations such as on the job or while driving. Information on the latter is rare and, in fact, it is difficult to find household surveys containing any information on both employment and alcohol measures. The choice of an alcohol measure is often dictated by availability as the few household surveys that combine information on employment and alcohol often do not offer many alternative measures of alcohol.

of the consumption based measures, heavy drinking is often of interest as it is likely to be of the greatest policy concern. Heavy drinking can be defined by any number of cutpoints defining the upper tail of the consumption distribution, often the 90 th percentile is a focus point. Heavy drinking is a consumption based measures that falls into our category of problem drinking.

The term 'alcoholism' denotes a alcohol-based problem diagnosed according to standardized definitions. For example, the American Psychiatric Association defines 'alcohol abuse' and 'alcohol dependence'. Alcohol dependence indicates, among other factors, manifestation of withdrawal symptoms and a build up of a tolerance. Abuse is, in essence, continued maladaptive or hazardous use of alcohol; such hazards can be physical, social, or psychological. The disorders of alcohol abuse and dependence are considered to be determined by both nature and nurture. In earlier work, we took advantage of the fact that these disorders are thought to have a large 
genetic component and as such could be considered to be exogenous in labor market equations. In this paper we seek to make comparisons across several different alcohol indicators.

There may be overlap between the categories. Heavy total drinking, many drinks per occasion, and consumption in harmful situations ${ }^{6}$ (e.g. on-the-job or while driving) are consumption related, but could overlap with individuals with a diagnoses of alcohol abuse and dependence. Heavy drinking and disorders should be fairly highly correlated at a point in time, however, some individuals who are considered to be 'recovering' alcoholics may currently be abstaining and some heavy drinkers will eventually develop alcoholism but have not yet done so.

Care should be taken in comparing alcohol/income results across studies to distinguish which category of measurement is being used and to consider how the indicator is measured empirically. Empirical studies of alcohol and labor market behavior are typically considerably constrained in the choice of the alcohol indicator; datasets combining employment measures and any alcohol indicators are rare and any given dataset typically has only a few feasible measures of alcohol.

All alcohol indicators could be viewed with some skepticism, as they are self-reported usually with little in the way of validity checks. However, most studies of the validity of self-reports have suggested fairly high correlation with alternative sources of

6. Data on the situations in which one drinks are important but are typically not available in existing data sets. If, for example, an individual has a few drinks before driving to work, the implications are likely to be different than if the individual has several drinks on returning home from work. 
information (e.g., Midanik, 1982 and 1989).

\section{ii. Demographic differences in problem drinking}

There are key systematic differences in alcohol consumption and alcohol abuse and dependence by demographic characteristics. Specifically, women are considerably less likely than men to be alcoholic, are more likely to abstain from consumption and have lower mean consumption levels (whether or not one adjusts for the higher percentage of abstaining females). There is also evidence that women respond physically to the ethanol somewhat differently than do men (Roman, 1985); for example, women metabolize ethanol faster than do men and also experience greater liver damage for consumption of the same levels of ethanol. There are also important differences by age. Youths are the heaviest drinking group and are also more likely to suffer from alcoholism. As they age, both men and women tend to reduce their consumption and are less likely to suffer from the symptoms of alcohol abuse and dependence. These differences by age and gender, and the corresponding differences in labor market behavior, combine to suggest that empirical analyses should consider combinations of age and gender groups separately (see also Mullahy and Sindelar, 1991 and 1993).

\section{iii. Alcohol impairment and employment problems}

Alcohol has been associated with a long list of physical, psychologic and cognitive impairments that can occur both in the short run and the long run (see NIAAA, 1994). Some of these adverse 
outcomes occur for continuously heavy drinkers (e.g. liver damage) while others can occur for even the occasional heavy drinker (e.g., automobile crash). Reduced hand-eye coordination, reduced concern for anything but alcohol ("alcohol myopia"7), significant time spent seeking alcohol, unusual or unstable behavior, increased accidents and injuries, liver and heart damage, among others, can all be associated with heavy alcohol consumption. Violence of various kinds is increasingly being viewed as associated with alcohol. These direct adverse outcomes can in turn have secondary effects. For example, drunk driving can results in injuries, hospitalization, and even arrest and revocation of a driver's license.

\section{All of these factors could reduce the productivity and} reliability of a worker or potential worker. First, there is the obvious impact of the accumulated short run negative effects of continued heavy consumption, e.g., a high rate of injury and continued absenteeism. In addition, reduced labor market experience, lower educational attainment (Cook and Moore, 1994; Mullahy and Sindelar, 1994), and a greater probability of divorce (Mullahy and sindelar,

7. Steele and Josephs (1990) present a survey of what they term the "alcohol myopia" phenomenon. They argue that although the immediate psychological effects of alcohol use are observed to differ across individuals and even differ for the same individual at different drinking episodes (e.g. happy drunks vs. somber drunks), there are at a different level some commonalities of the drinking experience.

In particular, the theory of alcohol myopia suggests that a common feature of alcohol use is that it reduces the spectrum of "signals" or "cues" to which the individual responds during the drinking episode. As alcohol intake increases during a drinking episode, remote, subtle second-order signals become blocked out as only the most immediate and prominent signals tend to be processed.

How might such myopia-seeking behavior be expected to have implications for employment outcomes? One possibility is that the immediate pleasures derived from the drinking episode are prominent to the senses while awareness about the employment implications of drinking too much on a Tuesday night -- e.g. I'll have to miss work tomorrow to nurse my hangover - - is screened out myopically as a remote or secondary signal. Running in the opposite direction, another possibility - not necessarily at odds with this one -- is that I am motivated to drink in order to seek the myopia that screen out my concerns about job-related troubles (hassles from co-workers, unemployment, etc.). Other possibilities can be imagined as well. 
1994; Kenkel and Ribar, 1994) are indirect effects that could mount over time. Also, by the time a person develops an alcohol-related disorder, they may be suffering from the adverse physical effects that occur with a long time lag, for example, cirrhosis of the liver. All of these problems that are associated with problem drinking could cause labor market problems for the drinker.

Heavy current alcohol consumption could have both short run and long run negative impacts on employment, possibly reducing earnings, increasing absenteeism, reducing employment and increasing unemployment. The long lag time between the earliest heavy consumption and some of these time-delayed adverse events suggests that the negative relationship between current alcoholism and current employment might not be as strong as the relationship between past alcoholism and current employment. On the other hand, as some adverse impacts of alcoholism can occur contemporaneously with consumption there could be a contemporaneous impact of alcohol on employment. An issue is what is the time period over which these potentially negative alcohol-related outcomes impact on earnings and employment.

\section{iv. Unemployment causes problem drinking?}

An alternative view of the direction of causality is found in the literature of sociology and alcohol research. In this literature it is thought that unemployment causes stress and this stress in turn causes increased alcohol consumption (e.g., Forcier, 1985). Unemployment is said to cause emotional and financial stress for an individual. The individual wants a job, but can not find one, suffers financially, and then consequently abuses alcohol. The increased 
stress of unemployment is said to cause increased and possibly excessive drinking ${ }^{8}$. While it is reasonable to consider short term unemployment as causing contemporaneous heavy drinking, it is more difficult to think of short term unemployment as causing the disorder of alcoholism as this syndrome typically takes a fair amount of time to develop. Neither increased nor excessive consumption of alcohol would necessarily cause alcoholism in the short run; the determination of alcoholism requires manifestation of symptoms over some period of time. Dependence requires the development of tolerance and addiction, which tend to take some time to develop. Thus, it is more likely that unemployment causes increased or excessive drinking, as compared to causing alcoholism. On the other hand, however, the unemployed could be expected to reduce consumption based on the reduced income alone (Ruhm, 1994); less money would be available to spend on alcohol. How the enjoyment from the increased leisure time fits into these relationships has not been discussed in the literature.

\section{v. Simultaneity}

Clearly, both of the above perspectives may be in operation simultaneously. Problem drinking may reduce employment and increase unemployment, and the reverse could be true as well. Indeed, a vicious circle may ensue. Alternatively, other factors may cause both employment and alcohol problems, such factors could include psychiatric problems, congenital or chronic health problems, injuries, physical pain, lack of ability to cope, problems with friends or 
family, frustration of one sort or another, or an unstable upbringing. From the perspective of a researcher, these factors may be difficult to observe and quantify. Thus the omitted variable problem is likely to occur in estimation of the alcohol/employment nexus, regardless of the perspective taken on causation.

Knowledge of the extent to which problem drinking causes unemployment or vice versa has important policy implications. If, for example, problem drinking causes higher unemployment, a productive policy might be to prevent and treat problem drinking. Such policies might have a very high marginal product as the subsequent adverse impacts such as unemployment and other alcohol-related costs would be reduced and employment would be increased. Alternatively, if it is found that unemployment causes problem drinking, a greater focus on policies to reduce unemployment, to develop skills to cope with the stresses of unemployment, or to mitigate the financial stresses could be warranted.

\section{B. Background Literature}

Researchers have explored a rich set of hypotheses on the relationships between drinking and productivity, efficiency, absenteeism, earnings, wages, work effort, and other measurable labor market outcomes.' For instance, there is a growing body of economics literature empirically assessing the impacts of alcohol use and problem drinking on income. Early studies found a consistently negative impact of problem drinking on income but were constrained by 
weak data (Berry and Boland, 1977; and Benham and Benham, 1982). More recent studies have taken advantage of improved data sources (Berger and Leigh, 1988; Cook, 1990; French and Zarkin, 1995; Mullahy and Sindelar, 1991, 1993, 1994a, and 1994b). While most studies continue to find a negative association between alcohol consumption and income, others have found positive impacts of alcohol on earnings (Berger and Leigh, 1988; Cook, 1990) or positive impacts of moderate consumption (French and Zarkin, 1995). Studies such as these finding a positive impact of alcohol have typically used consumption measures and have examined a set of workers only.

There has been little empirical research in the economics literature on the relationships between problem drinking and employment outcomes, the main topic of the present analysis. We briefly review the small set of extant literature in this area. Using a prominent st. Louis dataset described in Mullahy (1993), Benham and Benham (1982) found in raw data comparisons that alcoholics have an overall employment rate of $86 \%$ while the rate for the sample of psychiatrically "well" individuals and for the sample of non-alcoholics are $95 \%$ and $84 \%$, respectively. For full-time employment, the respective rates are $79 \%$ for alcoholics versus $90 \%$ for the well group and $78 \%$ for non-alcoholics. In regression models that control for other components of human capital, inferences about the relationships between problem drinking and employment (full- or part-time or military) are mixed: sometimes positive, sometimes negative, but in no instance even close to statistically significant. In a study of gender differences in the effects of alcoholism on employment, Mullahy and Sindelar (1991) found that for both females 
and males, alcoholism was associated with a negative impact on employment. We used multiple site data from the New Haven Epidemiologic Catchment Area (ECA). In simple cross-tabulations, we found that for all ages accept the youngest (18-29), that have ever met the criterion for alcohol abuse and/or dependence was associated with a lower employment rate. In regression analysis that controlled for other relevant covariates, we found a statistically significant negative impact of alcoholism on employment. The percentage reduction in employment ranged from .16 to .19 for women, depending upon what variables were included in the set of covariates. For males the corresponding range was .11 to .07. Invoking a criterion for employment far more stringent than that used by Benham and Benham, Mullahy and Sindelar (1993) found for the New Haven ECA sample of males that ever having met the DSM criteria for alcohol dependence or abuse is negatively and significantly related to full-time work propensity, 78\% for nonalcoholics versus $72 \%$ for alcoholics. The relatively small differences between alcoholics and non-alcoholics when pooled over all age groups mask striking differences seen for specific age groups. For males aged 30-44 and 45-59, the differences between the full-time work propensities of alcoholics and non-alcoholics are significant $(88 \%$ vs. $73 \%$ in the younger group, $86 \%$ vs. $68 \%$ in the older group). These significant negative effects of alcoholism carry over to a regression setting in which age, race, and other covariates are controlled.

Finally, using the NLSY dataset, Kenkel and Ribar (1994) use a variety of estimation strategies to examine the number of hours worked 
by young males and females. ${ }^{10}$ In their benchmark models, Kenkel and Ribar find only small labor supply effects of heavy drinking, negative and statistically significant for males, positive and statistically insignificant for females. Alcohol abuse has small positive, but statistically insignificant, relationships with labor supply for both males and females. Using instrumental variable methods, however, Kenkel and Ribar find considerably larger negative - - though statistically insignificant - effects of their problem drinking measures on hours worked for males, and considerably larger positive and statistically significant effects of the problem drinking measures on females' labor supply. ${ }^{12}$

With the exception of the Kenkel-Ribar study, a potential problem plaguing most of the existing literature on drinking and labor market success -- whether employment, wages, earnings, or income -- is reverse causation. That is, does problem drinking cause unemployment and low income or does lack of labor market success result in drinking problems? Previous research has been hampered in addressing this issue empirically by the lack of experimental and longitudinal data and by the fact that appropriate econometric instruments for problem drinking were not available in household data sets. We have maintained in our previous studies, however, that the simultaneity between employment and consumption may be more problematic (via the income effect among other paths) than that of alcoholism and

10. While numerous results are presented in the Kenkel-Ribar study, it is useful for purposes at hand to consider how their baseline (OLS) results compare with the results obtained using instrumental variable methods.

11. The contrasts between the Kenkel-Ribar results for males and females, as well as the differences in their baseline and instrumental variable estimates are useful to bear in mind when considering the empirical evidence we present later in the paper. 
employment, as alcoholism has a large genetic component.

One economic study, Ruhm, 1995, analyzed the extent to which unemployment was associated with alcohol consumption (and motor vehicle fatalities). Unlike the other studies described here which use household data, this study used states as the unit of observation. Ruhm found that alcohol consumption and unemployment were negatively correlated. A suggested interpretation of the findings was that unemployment reduces income which in turn reduces alcohol consumption. Turning to the literature in sociology, epidemiology and alcohol research, empirical studies have taken the opposite causal direction as their maintained hypothesis, that is, unemployment is considered the stressor that results in problem drinking. The empirical research in support of this contention has been very weak, initially drawing inferences from only samples of males who were in alcohol treatment programs; those in these samples were found to experience high unemployment rates. Even the more recent literature has not offered well structured analyses nor does it produce strong empirical support for unemployment as causing stress that causes alcohol abuse (see Forcier, 1985).

More recent literature focusing on women, debates the effect of employment per se may have on women. One hypothesis is that employment causes 'role' overload for women and this causes stress and thus alcohol problems. Another theory is that the working environment is conducive to drinking (e.g. stopping at a bar on the way home) and thus employment can cause increased alcohol consumption. Another view is that the issue is much more complicated and there are no simple generalizations (Wilsnack and Wilsnack, 1993). None of these 
contentions has received empirical scrutiny sufficient to draw any conclusions on causality.

This brief look at the literature in this area suggests several implication for our work. First, on a priori grounds, the direction of causality has not been established empirically. As suggested earlier, a likely scenario is that there is at least some reverse causality. A useful approach, then, would be to estimate unemployment as a function of problem drinking, using the instrumental variable approach for problem drinking. Second, comparisons across studies suggest that different measures of problem drinking might have different relationships with employment and unemployment. Further, there are indications that the alcohol/employment relationships might vary by age and gender. For example, the financial and emotional stress of being out of a job may be greater for middle aged married men than for middle aged married women, based on social norms of expected use of time. Youths may be more likely to expect some frictional unemployment so might not suffer as much stress from unemployment as would middle-aged individuals. Thus life cycle and gender differences might systematically affect the alcohol/employment relationship and thus could impact on the importance of using an IV estimation approach.

\section{CONCEPTUAL FRAMEWORK}

Consider a static neoclassical choice framework where households are price and wage takers. Labor supply decisions (L) and decisions about how much alcohol to consume (A) will both be choice variables that depend, in general, on all prices (P), wages (W), observable 
exogenous factors that affect household production $(\mathrm{X})$, and unobservable household characteristics $(\theta), i . e .$,

$$
A=A(P, W, X, \theta)
$$

and

$$
L=L(P, W, X, \theta)
$$

In this basic formulation, problem drinking (D) might be thought of as an adverse health outcome that arises from a health reduction function in which $A, L, X$, and $\theta$ are arguments,

$$
D=D(A, L, X, \theta)
$$

Yet the notion that there are causal or structural relationships running from problem drinking to labor supply and/or employment ${ }^{12}$ goes beyond reduced form choice functions like (1) and (2) or structural health reduction functions like (3), suggesting, in addition, a structural relationship like

$$
L=L(D, X, \theta ; \beta)
$$

The main focus of this paper is on models like (4). It is

\footnotetext{
12. To keep terminology simple, "employment" will be used in this section as a general term to describe any labor-supply-related outcome like hours, labor market participation, or actual employment. The term "labor supply" is thus used somewhat loosely here, since employment outcomes clearly depend on both labor supply and labor demand factors. Since an individual's productivity - - which may be affected by problem drinking status - - will clearly be a determinant of the demand for his/her labor services, it is probably more accurate to conceive of this analysis as an analysis of the determinants of labor market outcomes rather than labor supply decisions. However, in keeping with the terminology commonly used in the literature, we will sometimes refer to labor supply phenomena in this vein.
} 
useful to consider economic rationales for estimating such a structural relationship.

One possible interpretation of (4) is as a conditional leisure demand function, where conditioning is on problem drinking status. ${ }^{13}$ In this interpretation, D serves effectively as a "ration" of a commodity whose level affects the choice of $\mathrm{L}$. Interpreting the model as a structural conditional demand model is an approach that permits one to address directly the key policy question of interest, to wit: how do outcomes $L$ respond to changes in the "rationed" quantities of $\mathrm{D} ?^{14}$

An alternative interpretation of (4) is that it is a conventional labor supply function conditioned on an exogenous health status measure (D) in which prices and wages are omitted. While the omission of wages and prices is obviously problematic, the tradition of conditioning labor supply functions ${ }^{15}$ on health status is common in microeconometric research. Whether problem drinking can be considered such an exogenous -- i.e., uncorrelated with $\theta$-- determinant of labor supply/employment is obviously tenuous, although much of the economic literature on problem drinking and labor market outcomes to date has at least implicitly made this assumption.

Under either interpretation, the possibility that the measure of problem drinking is correlated with unobserved determinants of

\footnotetext{
13. See Phlips (1983), pp. 72-77, Browning and Meghir (1991), and Pollak and Wales (1992).

14. See Deaton and Muellbauer (1980), p. 125 .

15. Since earnings are the product of wage rates and the amount of labor supplied, the considerable literature on how health relates to earnings can be considered here as well.
} 
employment $(\theta)$ must be addressed if consistent estimates of the structural effects $L_{D}$ are to be forthcoming. The basic problem occurring when there is nonzero correlation between $D$ and $\theta$ in (4) is that standard regression methods will identify something like

$$
d L / d D=L_{D}+L_{\theta} d \theta / d D
$$

which will not equal the structural effect of interest $\left(L_{D}\right)$ so long as $\mathrm{d} \theta / \mathrm{dD}$ is nonzero.

The above discussion highlights the fact that somehow a wedge has to be driven between employment status and problem drinking status if claims about either one causing the other are to have any merits. In the absence of clinical randomization, researchers might, as an alternative, hope to find natural experiments that mimic the key attribute of experimental data, random assignment, ${ }^{16}$ or longitudinal data that might permit temporally persistent unobservables to be washed away.

Absent natural experiments or longitudinal data, instrumental variable estimation is the strategy most likely to be fruitful in such investigations. If it is reasonable, for instance, to maintain that some regressor or regressors in $\mathrm{X}$ are structural determinants of $\mathrm{D}$ but not of $\mathrm{L}$, then using these exclusion restrictions as the basis of defining instruments for $\mathrm{D}$ in (4) permits consistent estimation of $\mathrm{I}_{D}$

16. While one is hard pressed to imagine a situations where natural experiment would randomly assign individuals to alcohol abuse regimes in a manner independent of their employment status, it is perhaps less a stretch to conceive of circumstances where individuals might be randomly assigned to employment or unemployment in a manner independent of their problem drinking. For instance, a large plant that lays off many workers may be bound (e.g. by union rules) to allocate the layoffs in a manner unrelated to the distribution of drinking problems at the plant. Laid off workers would then be the "treatment" group while remaining workers would serve as controls. 
so long as the a priori restrictions are valid.

Theory often does not afford clear guidance as to the choice of appropriate zero restrictions, and the particular application considered here is no exception. Thus, although the strategy used in practice may, from a theoretical perspective, smack of being ad hoc, it is nonetheless true that certain restrictions are probably "more reasonable" than others. Further, two competing sets of estimates, one using instrumental variables and one not, provide the analyst with the basis of possibly useful specification tests. This is the basic idea underlying the econometric analysis conducted in section IV.

\section{DATA AND SAMPLE CONSTRUCTION}

\section{A. The 1988 NHIS Alcohol Survey and Problem Drinking Measures}

The main data source used in this study is the 1988 Alcohol Survey of National Health Interview Survey (NHIS) which is a stratified, multistage probability sample of the U.S. population. The NHIS core survey gathers data on socioeconomic characteristics and health conditions for about 49,000 households, yielding approximately 150,000 individual observations. Through an arrangement with the National Center for Health Statistics, we were able to match the 1988 NHIS records to state-level data on labor market conditions, alcoholic beverage excise taxes, and other data pertinent to drinking behavior and/or labor market outcomes.

The 1988 version of the NHIS included a detailed Alcohol survey for which one adult (18 years and older) from each household was randomly selected as a respondent. There are over 43,000 observations in the overall Alcohol survey which obtains individual data on 
drinking patterns, symptoms of alcoholism, family history of alcoholism, and other individual characteristics.

The NHIS Alcohol Survey elicits responses to a battery of questions on alcohol-related symptoms. These responses are used as inputs into an algorithm to obtain diagnoses of alcohol abuse and dependence according to the American Psychiatric Association's DSM-III-R classification system (American Psychiatric Association (1987)). According to these criteria, "psychoactive substance dependence" (i.e. dependence) involves withdrawal and tolerance as well as maladaptive use of alcohol despite adverse consequences to the individual. Abuse is considered maladaptive use of alcohol; the individual has continued (for a duration of at least one month) use of alcohol despite knowledge of the adverse effects, yet the individual does not meet the criteria for dependence. We pool the categories of alcohol abuse and dependence. There is a relatively large overlap empirically, according to Grant et al. (1991), and much of the alcohol literature combines the two categories.

Following Grant et al. (1991), we developed an algorithm to assess alcohol dependence and abuse. ${ }^{17}$ We focus here on symptoms occurring in the past year. When using clinically-based definitions of diagnoses with household survey data some adjustments must be made. For example, the DSM-III-R definition of alcohol abuse and dependence requires that symptoms have existed for a month or longer. However, household surveys typically -- and the NHIS in particular -- ask only about the frequency of symptoms rather than their duration. Thus, 
frequency criteria (e.g., two times per year or more) can be used instead of duration criteria. Grant et al. (1991) use this approach. ${ }^{18}$ We formulate a variable, ABUSE/DEPENDENCE, which indicates whether an individual meets the criteria for either alcohol abuse and/or alcohol dependence, using the screen of having exhibited a symptom twice per year.

The Alcohol Survey also asks about alcohol consumption during the two weeks previous to the survey. The questionnaire asks separately about consumption of beer, wine, and distilled spirits. From data from these responses, we formed a composite indicator of total ethanol consumption ${ }^{19}$. We used the total two week ethanol consumption as one measure of alcohol in our analyses. We use this alcohol measure to make comparisons to other studies in the literature. However, our focus is on problem drinking, not average consumption levels ${ }^{20}$. Thus, given our focus on problem drinking, we define several indicators of heavy drinking. As indicators of heavy drinking, we use as cutpoints both the 90 th and 95 th percentile in the distribution of the observed ethanol consumption for our sample population (we include abstainers in calculating the distribution). The percentiles are calculated separately for the distribution of males and females; we

28. Recall from the definitions of the problem drinking variables that they are designed to determine whether an individual was an alcohol abuser and/or was alcohol dependent at some time during the twelve months preceding the interview. Since the 1988 NHIS interviews take place during the entire 1988 calendar year, this implies that measured abuse and/or dependence could have occurred as early as January 1987 (for individuals interviewed in January 1988) or as late as December 1988 (for individuals interviewed in December 1988).

29. There is mounting evidence suggesting that the beer tax may have important effects on alcohol use, alcohol misuse, drunk driving behavior, etc., when it functions as an inhibitor to consumption, particularly among younger individuals. See, e.g., Grossman (1989), Grossman et al. (1993), Mullahy and Sindelar (1994), and Saffer and Grossman (1987). Apparent ethanol consumption is used under the assumption that an individual's "alcohol consumption environment" may have important effects on drinking behavior. 
use gender specific percentiles based on the evidence that women and men have different physiological responses to alcohol; there may also be different psychological and social difference as well. The 90th and 95 th percentile are for males, 18.0 and 28.8 ounces, and for females 5.8 and 10.8 ounces per two week period. These indicate the large differences by gender in the distribution of alcohol consumption.

\section{Employment Measures}

The employment measures used in this study are consistent with standard definitions of labor market status. Labor market analysts typically find it useful to distinguish three states of labor market participation: "employed," "unemployed," and "out of the labor market." Individuals in the first two categories are considered labor market participants while those in the third category are overlap. The NHIS provides information on the individual's labor market status in the past two weeks, which we will refer to as "currently". From this data, we formed two binary labor market status variables for this analysis: EMPLOYED and UNEMPLOYED, which correspond to the "currently employed" and "currently unemployed" categories described above. ${ }^{21}$ out of the labor force is the omitted category.

\section{Descriptive Statistics}

We follow the strategy pursued in our earlier work (Mullahy and

21. It might be pointed out here that while the 1988 NHIs is the first large dataset providing problem drinking diagnoses consistent with DSM criteria, the labor market information available is scanty. Although the employment measures used here are standard ones, the survey contains no information on wages, earnings, or even individual income. 
Sindelar (1993)) and restrict attention to a sample composed of adults in the age range of 25 to 59 years old. For most of this group, schooling will be completed, retirement will not be a widespread phenomenon, and the prevalence of problem drinking behavior will be relatively homogenous, at least in comparison with the entire over-18 population. The reasons for examining this age range include that both labor market and drinking behavior for the young and the elderly are generally qualitatively different from that of individuals in the prime working years. The young have a greater than average prevalence rate for alcoholism and are also more likely to be in school, just entering the labor market after school, and/or combining school and market work. These considerations suggest that it may not be reasonable to pool all age categories together in the analyses. Our earlier work and well-known gender differences in drinking and labor force participation also support the separate analysis by gender. Table 2 displays the sample descriptive statistics for males $(\mathrm{N}=10421)$ and females $(\mathrm{N}=13384)$ separately aged 25 to 59 . For all variables except those that are related to reports of alcohol consumption, the sample here is defined to be those observations for which there is a valid observation on each variable in this list. As can be seen in the table, alcohol consumption related variables are missing for $6.8 \%$ of the above described sample for women and $5.7 \%$ for men. This difference in sample selection may be of importance as, in our data, individuals that have missing observations on consumption are systematically more likely to be alcohol dependent or abusive. For regression analysis of ABUSE/DEPENDENCE, as seen in Table 4, we used the larger sample of individuals who had valid responses on this 
indicator and all the control variables. For regressions of ETHANOL, 90th PERCENTILE and 95th PERCENTILE HEAVY DRINKING, we used the somewhat smaller sample.

As can be seen from table 2, ABUSE-DEPENDENCE is roughly three times more prevalent among males than females: 15 percent of males either abuse alcohol or are dependent on it, while 5 percent of females have such a drinking problem. Men are more likely than women to be employed (.898 versus .693), but perhaps surprisingly, men are slightly less likely to be unemployed ${ }^{22}(.032$ versus .036). The mean value for ethanol intake is dramatically higher for men, indicating their overall higher consumption of alcohol. As the heavy drinking percentiles are defined to be gender specific percentiles, the percentiles do not vary across male and females although the cutpoints do vary by gender.

\section{ECONOMETRIC STRATEGY}

\section{A. Modeling Considerations}

The prototype of the structural model we wish to estimate is given by (4). Given our data, the two key attributes of this model that must be accounted for in the econometric analysis are the multinomial structure of the outcome variable (employed, unemployed,

22. While the analysis here is positive rather than normative - in keeping with most of the empirical labor supply literature - it is appropriate at this point to note that terms like "employment" and "unemployment" of ten connote "good" and "bad" outcomes in common parlance. For the purposes at hand, however, some caution is advised in drawing such connotations. It may be, for instance, that "not in the labor force" is the outcome preferred, all else equal, for some individuals (perhaps, on average, more frequently for females than for males). In most imaginable cases, however, unemployment is probably a "bad" outcome in the sense of being dominated by either employment or not being in the labor force or both.

In the following discussion, however, we will sometimes casually discuss results as if increases in factors that decrease employment propensity and increase unemployment propensities are "problems" or "problematic" with the above proviso in mind. 
not in the labor force), and the potential nonzero correlation between the problem drinking measures and the unobserved determinants of the labor market outcomes. ${ }^{23}$

We use an estimation strategy that was suggested by the work of Heckman and MaCurdy (HM) (1985), itself an extension of ideas first proposed by White (1982) (specifically for the linear model) and Hansen (1982) (who provided the general results for such generalized method of moments (GMM) estimators). We will refer to this method as the HM/GMM method. The basic idea underlying the HM/GMM estimator for binomial or multinomial outcome models is to characterize the equation describing the probability of each outcome conditional on observed covariates $(x)$ as well as unobservables $(\theta)$ as a linear-in-parameters function of $x$ and $\theta$. Since conditional probabilities are conditional expectations in probability models, the GMM approach based on such expectations can then be used for estimation of and inference about

23. It is useful to consider briefly several alternative approaches and the reasons we have chosen not to utilize them so that the reader might better appreciate the rationales for selecting the methods we utilize.

One possibility we considered was to expand the framework suggested by Amemiya (1978) for the analysis of structural probit models to a multinomial outcome setting. We considered such an approach to be both computationally difficult as well as requiring for consistency a proper specification of the reduced form for the endogenous variables. By "proper specification of the reduced form" we mean not just utilizing appropriate instrumental variables, but also using the proper functional form linking the expectation of the endogenous variables conditional on the instruments to the instruments. Most of the literature to date has considered linear reduced forms, but since the endogenous variables we are concerned with are binary, linearity of their reduced forms is questionable.

Additionally, we might note that in an earlier version of this paper, we did estimate some binary outcome specifications (i.e. employed vs. either unemployed or not in the labor forcel using Amemiya's method

Another alternative would be to assume a standard probability model for multinomial outcomes (e.g. multinomial logit) and use a "plug-in" approach whereby the reduced form of the endogenous variable is estimated consistently, the true value in the covariate vector is replaced by the resulting predicted value, and the model is estimated by standard methods (e.g. maximum likelihood). While this approach can produce consistent estimates under certain circumstances, consistency will generally not obtain if the assumed probability model (e.g. logit) is wrong or if the reduced form for the endogenous variable is misspecified. Even if these problems are surmounted, obtaining a consistent estimate of the parameter covariance matrix will often be a challenging task. 
the parameters determining the conditional probabilities.

The HM/GMM approach is a true IV estimation approach in the sense that it is based on moment functions $m(\alpha)=z^{\prime}(y-x \alpha)$ that have (ignoring the possible approximation error) zero expectation if the instruments $z$ are valid. Correct specification of the reduced forms for the endogenous variable(s) is not required, as it would be for consistency of the other approaches to obtain. The main drawback of the HM/GMM approach involves the extent to which the linear probability model is or is not a good approximation to the true probability model. With this caveat in mind, we proceed now to describe the linear probability framework within which we will work.

\section{B. Estimation strategy}

Let $y_{j t}$ denote the indicator variable for outcome $j$ and individual $t, i . e . y_{j t}=1$ if individual $t$ has outcome $j, y_{j t}=0$ if individual $t$ has outcome other than $j$. Then

$$
\begin{aligned}
E\left(y_{j t} \mid x_{t}, \theta_{t}\right)=\operatorname{Pr}\left(y_{j t}=1 \mid x_{t}, \theta_{t}\right) & =F\left(x_{t} \beta_{j}+\theta_{t}\right) \\
& \approx F(0)+F^{\prime}(0)\left(x_{t} \beta_{j}+\theta_{t}\right) \\
& =\alpha_{j 0}+x_{1 t} \alpha_{j 1}+\gamma_{j} \theta_{t} .
\end{aligned}
$$

so that, approximately,

$$
\begin{aligned}
y_{j t} & =\alpha_{j 0}+x_{1 t^{\prime 1}}+\varepsilon_{j t} \\
& =x_{t} \alpha_{j}+\varepsilon_{j t^{\prime}}
\end{aligned}
$$

where $x_{t}=\left[1, x_{1 t}\right]$ is a $1 \times k$ vector of observed explanatory variables (including now the problem drinking measure, $D$ ) with $x=\left[x_{t}\right]$ being the 
corresponding $\mathrm{T} \times \mathrm{k}$ matrix of stacked observations; $\theta_{t}$ is a scalar summarizing unobserved determinants of the outcomes, which may be correlated with some elements of $x_{t} ; Y_{j}=\left[y_{j t}\right]$ is the $T \times 1$ vector of indicator variables for outcome $j$, with $j=1$ denoting employment and $j=2$ denoting unemployment, with the omitted third outcome of not being in the labor force $i^{24} F($.$) is some distribution function giving the$ outcome probabilities; $\beta=\left[\beta_{1}, \beta_{2}\right]^{\prime}$ are the "true" structural parameters; $\alpha=\left[\alpha_{1}^{\prime}, \alpha_{2}^{\prime}\right]^{\prime}$ are the parameters that are the object of estimation in the linear probability context, the slope parameters of which are approximately equal to $F^{\prime}(0)$ times the respective slope parameters in $\beta$; and $\varepsilon_{j t}$ captures the unobserved components of the model $\left(\theta_{t}\right.$ as well as the stochastic variation of $y_{j t}$ around $\left.E\left(y_{j t} \mid x_{t}, \theta_{t}\right)\right)$ and the approximation error involved in moving from $F($. to the linear probability model. ${ }^{25}$

The model to be estimated can be summarized as follows. The structural equations are

$$
\underline{\mathbf{Y}}=\underset{\sim \sim}{\mathbf{X} \alpha}+\underline{\varepsilon}
$$

where

24. One way to think about the normalization implicit here is to recognize that $\alpha$ and $\alpha_{2 k}$ give the partial structural effects on outcomes 1 and 2 , respectively, holding evkrything else constant. If a model for outcome 3 were specified explicitly, the corresponding $\alpha_{3 k}$ parameter would equal $-\left(\alpha_{1 k}+\alpha_{2 k}\right)$, i.e. $\alpha_{1 k}+\alpha_{2 k}+\alpha_{3 k}=0$. While the model is cast ${ }^{2}$ a probability framework, it may be easier 顼r purposes of interpretation to think about these parameters as conditional expectation effects. The implied normalization also means that the coefficients on outcomes 1 and 2 can be added together to obtain the contrast between the not in the labor force vs. in the labor force effects.

25. Note that the approximation is second-order when the density $f(0)=F^{\prime}(0)$ is differentiable and has a mode at zero (e.g. normal, logistic, etc.). Note, too, that while the approximation error is typically given greater attention in the linear probability context than elsewhere, such errors of approximation are also involved when the wrong $F($.$) is assumed by the analyst, e.g. when logit is assumed but probit is$ true. 


$$
\begin{aligned}
& \mathbf{Y}=\left[\begin{array}{lllll}
\mathrm{Y}_{1}^{\prime} & \mathrm{Y}_{2}^{\prime}
\end{array}\right]^{\prime} \quad(2 \mathrm{~T} \times 1) \\
& \mathbf{X}=\mathrm{I}_{2} \otimes \mathrm{X} \quad(2 \mathrm{~T} \times 2 \mathrm{k}) \\
& \tilde{\varepsilon}=\left[\varepsilon_{1}^{\prime} \mid \varepsilon_{2}\right]^{\prime} \quad(2 \mathrm{~T} \times 1)
\end{aligned}
$$

and

$$
\underline{\alpha}=\left[\alpha_{1}^{\prime} \mid \alpha_{2}^{\prime}\right]^{\prime} \quad(2 \mathrm{k} \times 1)
$$

The HM/GMM criterion function is given by

$$
\underset{\sim}{Q} \underset{\sim}{\alpha}=\underset{\sim}{\mathbf{X} \alpha})^{\prime} \mathbf{Z}\left(\mathbf{Z}_{\sim}^{\prime} \mathbf{z Z}\right)^{-1} \mathbf{Z}_{\sim}^{\prime}(\mathbf{Y}-\underset{\sim}{\mathbf{X} \alpha})
$$

where

$$
\mathbf{z}=I_{2} \otimes \mathrm{Z} \quad(2 \mathrm{~T} \times 2 \mathrm{p})
$$

with the instruments given by $z=\left[z_{t}\right]$, where $z_{t}$ is a $1 \times p$ vector that may share some elements in common with $x_{t}$, and

$$
\underset{\sim}{\boldsymbol{\Sigma}}=\left[\begin{array}{ll}
\Sigma_{11} & \Sigma_{12} \\
\Sigma_{21} & \Sigma_{22}
\end{array}\right]=E\left(\underline{\left.\varepsilon \varepsilon^{\prime}\right)} \quad(2 \mathrm{~T} \times 2 \mathrm{~T})\right.
$$

where the $\Sigma_{i j}$ are diagonal. The parameter estimates are closed form and are given by

$$
\hat{\alpha}=\left[\mathbf{X}^{\prime} \mathbf{Z}\left(\mathbf{Z}_{\sim}^{\prime} \hat{\Sigma} \mathbf{Z}\right)^{-1} \mathbf{Z}_{\sim}^{\prime} \mathbf{X}\right]^{-1} \mathbf{X} \cdot \mathbf{Z}(\mathbf{Z} \cdot \hat{\Sigma} \mathbf{Z})^{-1} \mathbf{Z}_{\sim}^{\prime} \mathbf{Y}
$$

whose asymptotic covariance matrix can be estimated consistently by

$$
\left.\hat{\mathrm{V}}(\underset{\sim}{\hat{\alpha}})=\underset{\sim}{\mathbf{X}} \underset{\sim}{\mathbf{z}}\left(\underset{\sim}{\mathbf{z}} \hat{\Sigma}_{\sim \sim} \mathbf{z}\right)^{-1} \underline{\mathbf{z}}^{\prime} \mathbf{x}\right]^{-1}
$$


where the preliminary estimate $\boldsymbol{\Sigma}$ is obtained using residuals from separate 2 SLS estimation of the equations for $Y_{1}$ and $Y_{2} \cdot{ }^{26}$

In the overidentified case, Hansen (1982) has shown that the GMM approach provides a straightforward test of overidentifying restrictions, as the value of the criterion function evaluated at the estimated parameters, $Q(\underline{\alpha})$, has asymptotically a $\chi^{2}$ distribution with $\mathrm{p}-\mathrm{k}$ degrees of freedom under the null hypothesis of orthogonality between $\varepsilon$ and $\mathbf{z} .{ }^{27}$

\section{Specification of Covariates and Instrumental Variables}

The $\mathrm{X}$ vector of structural covariates is specified to include AGE, $\mathrm{AGE}^{2}$, SCHOOLING, FAMILY SIZE, WHITE, MARRIED, the health status variables (EXCELLENT, VERY GOOD, GOOD, FAIR, with poor health status the excluded baseline category), the regional variables (NORTHEAST, MIDWEST, SOUTH, with west region the excluded baseline category), the metropolitan area variables (CENTER CITY, OTHER MSA, with non-MSA the excluded baseline category), and the state level of unemployment for 1988 (UE88). The latter (UE88) is included as a labor demand shifter. The structure of the 1988 NHIS data on problem drinking and employment outcomes works reasonably well from a causal model

\footnotetext{
26. Note that this estimator is the multiple-equation version of the two-stage instrumental variable (2SIV) estimator proposed by white (1982).

27. Despite the renowned low power of such tests, the probability of rejecting the null of orthogonality between instruments and unobservables becomes quite high when standard significance criteria are employed given the large sample sizes analyzed here. Accordingly, in the analysis undertaken below, the overidentification test statistics are judged at both standard significance levels as well as at the criteria proposed by Schwartz (1978) (i.e. the log of the sample size times the degrees of freedom of the test). See Deaton et al. (1989) for an application of this idea.

It should also be stressed that error-instrument orthogonality, while important, clearly does not guarantee that the IV results are reasonable, e.g. using generated random numbers as instrumental variables would give orthogonality.
} 
perspective. In the case of current consumption (e.g., drinks in the past two weeks), there could well be a contemporaneous effect on employment. In the case of alcohol abuse/ dependence, "current" employment status (i.e., employment status in the two weeks preceding the survey interview) is conditioned on "lagged" problem drinking (i.e., abuse or dependence occurring sometime during the twelve months preceding the interview $\left.{ }^{28}\right)$. It would not be reasonable to maintain causality if the employment status precedes the diagnosed disorder in our setup. The conditioning of labor supply on problem drinking (eq. (4)) enabled by our data would thus seem empirically reasonable. In the IV strategy that we pursue, we use as instrumental variables all the variables in the $\mathrm{X}$ vector except the problem drinking measure. In addition, we use the state-level excise tax on beer, ${ }^{29}$ the state-level excise tax on cigarettes (a complementary good), and state-level apparent ethanol consumption (a measure of per capita state-level sales). ${ }^{30}$ We also include the quadratics of the

28. Recall from the definitions of the problem drinking variables that they are designed to determine whether an individual was an alcohol abuser and/or was alcohol dependent at some time during the twelve months preceding the interview. Since the 1988 NHIS interviews take place during the entire 1988 calendar year, this implies that measured abuse and/or dependence could have occurred as early as January 1987 (for individuals interviewed in January 1988) or as late as December 1988 (for individuals interviewed in December 1988).

29. There is mounting evidence suggesting that the beer tax may have important effects on alcohol use, alcohol misuse, drunk driving behavior, etc., when it functions as an inhibitor to consumption, particularly among younger individuals. See, e.g., Grossman (1989), Grossman et al. (1993), Mullahy and Sindelar (1994), and saffer and Grossman (1987). Apparent ethanol consumption is used under the assumption that an individual's "alcohol consumption environment" may have important effects on drinking behavior.

30. Given the arguments presented above, we contemplated initially using both 1988 and 1987 measures of these variables. Since the correlations of the 1988 and 1987 measures for all these variables is quite high, little additional information is gained -- and noise is introduced -- by including both years' measures. As such we use only the 1987 measures of these variables.

A more formal justification for using lagged measures would recognize that lagged taxes are reasonable instruments given the possibly habitual/addictive nature of alcohol use and that lagged apparent ethanol is a reasonable instrument on the basis of a "social interactions" type model (Becker (1974)) in which my consumption this 
two taxes and apparent ethanol. Additionally, we use three variables describing a history of living with alcoholic relatives in one's youth (under age 18). These variables indicate whether an individual lived with a biological mother, biological father, or any relative who is reported by the respondent to have been alcoholic ${ }^{31}$. These family variables are included on the premise that they characterize some important aspects of an individual's "initial conditions." Whether it is a priori reasonable to exclude these variables from the structural labor supply model is debatable since it is clearly possible that such measures characterize aspects of an individual's early home environment that structurally affects labor supply propensity ${ }^{32}$

\section{RESULTS}

We first undertake some simple comparisons of employment status and several different measures of problem drinking in order to establish some baseline relationships which can be compared to the multivariate regression results. Then using OLS, we examine how these baseline relationships are affected by consideration of relevant exogenous covariates. The last step is to determine how the IV

period depends on my neighbors' consumption in the previous period.

31. Before proceeding to a discussion of the results, we note here the important and increasingly studied issue of IV bias (Nelson and startz (1990), staiger and stock (1993)). When the excluded instrumental variables are poor, in the sense that they explain little of the variation in the included endogenous variable(s), it has been demonstrated that IV estimates can have far more serious biases than oLs. We explored the explanatory power of our excluded variables. Because there might be some concern that the variables indicating that a person lived with an alcoholic when growing up might be endogenous, we estimated a linear probability regression of the ABUSE/DEPENDENCE measure on the three other instrumental variables, that is, beer tax, cigarette tax and apparent ethanol. The F-statistics for are $F(3,13380)=5.2$ for females and $F(3,10417)=8.5$ for males; these would be significant at better than the . 99 level by conventional criteria, but would not be significant if judged by the schwartz criterion.

32. Kenkel and Ribar (1994) pursue an analogous strategy in their structural model estimation. 
structural analysis changes the conclusions drawn from the previous two steps.

\section{A. Baseline Results}

Table 3 presents the sample means of the employment status variables (EMPLOYED, UNEMPLOYED) by problem drinking status ("No PD" indicates individuals not having that particular problem drinking diagnosis; "PD" signifies individuals who do). As the table indicates, males who are problem drinkers are less likely to be employed and more likely to be unemployed ${ }^{33}$. These differences in the raw data support the concept that problem drinking, however defined, results in adverse labor market outcomes for males. Problem drinking as measured by the 95th PERCENTILE is associated with the lowest employment rate and one of the greatest unemployment rate for males.

Interestingly, for females both unemployment and employment propensities are greater for the problem drinkers. ${ }^{34}$ For females, ABUSE/DEPENDENCE is associated with the highest unemployment rate and problem drinking as defined by the 95th PERCENTILE is associated with the lowest employment. The comparisons for females are somewhat surprising in that employment and problem drinking are positively

33. Note that in this sample, males having no drinking problems have on average higher employment propensities and lower unemployment propensities than do females in the corresponding categories. Similarly, problem drinking males have higher employment and lower unemployment rates than females, ceteris paribus; the exception to this is that males who drinking is above the 95 th percentile for males have a slightly higher unemployment rate than do similar women. Recall, however, that the 95th percentile is defined to be gender specific. The greater employment probabilities for males are merely a refection of the overall greater propensity of males to be employed.

34. Mullahy and sindelar (1991) document a variety of male-female differences in labor market outcomes. 
associated. However, this finding is consistent with some previous findings (Kenkel and Ribar, 1994).

One must be careful in interpreting these cross-tabulations as indicating that alcohol problems are 'good' for women by increasing their employment. First, there is the obvious issue of establishing casualty, but beyond that is the additional issue of identifying a desirable outcome. It may be more difficult to interpret such employment statistics for women than for men as 'desirable' and 'undesirable' from the individual's perspective. Most prime aged men want to be employed, ceteris paribus. However, women may be more heterogeneous in what constitutes their desired employment state. Some women may want to work but cannot find a job. These women may be categorized as either unemployed or 'discouraged'. Some women, may have financial need to work, but would prefer, holding all else constant, to work in the home. That is, being employed in the labor market is not necessarily the desired outcome for all females. ${ }^{35}$ One would need more specific individual level data on the desired employment states in order to establish how problem drinking affects women's abilities to achieve their employment goals.

\section{B. OLS and IV Results for Problem Drinking}

Table 4 summarizes the problem drinking coefficients estimates for several measures of problem drinking. The table displays the oLS

\footnotetext{
35. A plausible scenario would be as follows: a woman with an alcohol problem may have children at home with whom she would like to stay, but financially she needs to work as her alcohol problem caused her divorce and now she has no husband to help monetarily (sindelar, forthcoming). Thus, the alcohol problem is positively associated with employment, but an interpretation of employment as a 'good' outcome may be incorrect.
} 
and IV results for males and females separately of the point estimates and corresponding t-statistics for the problem drinking measures. The coefficients on the non-alcohol covariates remain relatively stable across the alternative measures of problem drinking for both the OLS and the IV regressions. Thus, to economize on space, we present the full results only once for each males and females. We present a representative case for each gender in Appendix tables A1 (males) and A2 (females). Tables A1 and A2 show the full set of estimated parameters using the 90 th percentile cutoff as the problem drinking indicator. The full results underlying all the estimates in table 4 are available on request from the authors. We summarize the findings for non-problem drinking covariates in a sub-section below.

\section{i. OLS estimates}

The OLS estimates for males substantiate the same relationships that were found in Table 3 for the baseline comparisons. That is, even when controlling for relevant covariates, problem drinking is associated with lower employment and higher unemployment for males. Specifically, relative to non-participation in the labor market, the OLS results reported in Table 4 suggest that, controlling for observed covariates, males who have had drinking problems are less likely to be employed and more likely to be unemployed than those without drinking problems. In magnitude, ALCOHOL ABUSE/DEPENDENCE and 95th PERCENTILE DRINKING would appear to have the most serious impact on employment and unemployment, although ALCOHOL ABUSE/DEPENDENCE is the more significant of two indicators. Note that, as expected, the coefficients on ethanol consumption are insignificant and of very 
small magnitude. This confirms our view that consumption per se is not detrimental, but rather it is problem drinking that has adverse effects on employment.

Turning to females, again the findings of the baseline comparisons in Table 3 are largely confirmed. That is, problem drinking tends to be associated with increases in both employment and unemployment. The exception to this generalization is the negative coefficient on 95th PERCENTILE for employment. The coefficients on problem drinking for employment are insignificant while in contrast, those for unemployment are significant, with the exception of the insignificant coefficient on ethanol consumption.

These correlations do not, of course, identify the structural effects that are of primary interest. The econometric analog of (5) is that these OLS results identify

$$
\alpha_{\mathrm{D}}+\sigma_{\mathrm{D} \varepsilon}\left(\sigma_{\mathrm{DD}}-\sigma_{\mathrm{DX}}^{2}\right)^{-1}
$$

where $D$ stands for problem drinking, $\alpha_{D}$ is the structural effect of interest (the impact of problem drinking on employment, say), and $\mathrm{X}$ summarizes all other covariates with $\sigma_{\mathrm{XX}}$ normalized to 1 and $\sigma_{\mathrm{X} \varepsilon}$ assumed to be zero. Since $\left(\sigma_{\mathrm{DD}}-\sigma_{\mathrm{DX}}^{2}\right)>0$ in this instance, the direction of the OLS bias is determined by the sign of $\sigma_{\mathrm{D} \varepsilon}$.

Since larger values of $\varepsilon$ represent unobserved factors that positively influence employment outcomes, then the interpretational issue amounts to what is the likely correlation between such factors and problem drinking propensity. Suppose the employment outcome of interest is a continuous labor supply measure. Then the issue is 
whether unobserved factors that positively influence labor supply exert net positive or net negative influences on problem drinking propensity. Stories can be told that are consistent with either a positive or a negative $\sigma_{D E} \cdot{ }^{36}$ While their primary utility is in providing what we hope are consistent estimates of the structural effects $\alpha_{D}$, a by-product of the IV estimates we discuss is an implicit sense of the nature of such $\sigma_{D}$ correlations.

\section{ii. IV results}

The interesting results come when we compare the ols results to those of the IV. For males, the same conclusions were seen in both the cross-tabulations and the oLs results; for males, problem drinking is detrimental to employment and increases unemployment. The difference here is that the magnitude of the effect is much greater for the IV results; the magnitude of the effects are about 6, 9, and 16 times greater as compared to the oLs results for, respectively, ABUSE/DEPENDENCE, 90 th PERCENTILE, and 95th PERCENTILE. Somewhat surprisingly, the significance level increases slightly for the 95 th PERCENTILE indicator. The significance level decreases only slightly for the 90th percentile and, as might be considered more common in going to an IV approach, the significance level decreases quite a bit for ABUSE/DEPENDENCE. Turning to the results for unemployment the same pattern emerges, but the magnitude of the change is slightly more subdued. The IV estimates are about 3 to 10 times greater than the OLS results and the significance levels decline in going to the IV approach. The 95th PERCENTILE drinking indicator has one of the

36. See Mullahy (1993) for further discussion. 
biggest impact in the cross-tabulations and remains as having one of the greatest impacts in the OLS results; in the IV results, the 95 th PERCENTILE continues to produce the greatest impact on employment and unemployment.

For males, these results substantiate the generally detrimental effect of problem drinking on employment propensity. When we control through IV for unobserved heterogeneity, the magnitude of the detrimental effect increases, suggesting that the OLs results underestimate the size of the negative impact, assuming of course, that our IV instruments are good instruments.

For females, the IV results are even more interesting as they change the sign on the employment variables from the positive effect on employment in the case of OLS to a negative impact for the IV approach. By conventional standards, the parameter estimates are insignificant in all cases, so strong inferences can not be made. However, it is interesting that when unobserved heterogeneity is controlled for, to the extent allowed by our instruments, the puzzling positive impact of problem drinking for women disappears. Instead the IV results conform more to the concept of a detrimental impact of problem drinking on employment, as is found for men. These IV results contrast to the OLS results and also to the raw data displayed in the cross-tabulations. The transformation due to the IV approach is consistent with the idea that for women, labor market choices are more complicated, with women having less uni-dimensional employment goals. That is, for women, employment is not necessarily the preferred state. Unobserved heterogeneity may play a more important role for women in these employment/alcohol relationships. 
Turning to the unemployment results for women, the IV results produce substantially higher estimates of the impact of problem drinking on unemployment. The coefficients increase from over 2 times to about 8 times, with the biggest change occurring for the indicator of the 95th PERCENTILE, as was also true for men. As might be expected, the IV coefficients are less significant for the unemployment regressions as compared to the oLs results.

Taking the oLS results on employment and unemployment as set for women would suggest that problem drinking is strongly associated with an increase in labor force participation. Recall that the sum of the EMPLOYMENT and UNEMPLOYMENT point estimates gives the net impact of problem drinking on labor market participation. ${ }^{37}$ However, the IV results suggest that the net impact on labor force participation is less clear. While problem drinking appears to be associated with an increase in the unemployment rate, it is also associated with a decrease in the employment rate. Considering the magnitude of the IV magnitude coefficients, and for the moment ignoring the significance level, suggests that on net, problem drinking reduces labor force participation for women, as it does for men.

The IV estimates suggest that problem drinking has the same pattern of effects for both men and women, reducing employment and increasing unemployment. In fact, the IV point estimates of problem drinking in regressions of employment are very similar by gender. The simlarity is striking and somewhat surprising given both the differences in the raw data and also in the oLs estimates by gender 
and the fact that ABUSE/DEPENDENCE picks up a considerably smaller percentage of the female sample as compared to the male sample; $15 \%$ of the males and 5\% of the females are found to be abusive or dependent.

\section{iii. Overidentification tests}

Table 4 also displays the Hansen overidentification test statistics corresponding to the IV estimates. Using conventional statistical criteria, for males and females the null of orthogonality between instrumental variables and unobservables is rejected at the .05 significance level for only one of the three problem drinking measures, and then so only marginally. For females, none of the three tests recommends rejection. It should be noted that tests of this nature are known to have low power in many circumstances, so failure to reject should not necessarily be taken to be a solid indicator of instrument set acceptability.

\section{iv. Covariates}

Here we briefly summarize the results on non-problem drinking covariates. As stated above, the appendix displays a full set of results for one representative problem drinking indicator. Most of these results do not differ importantly between OLS and IV, so the discussion will be kept at a fairly general level. For both males and females, and regardless of estimation strategy, the UE88 unemployment estimate is statistically significant and has the expected signs: negative for employment, positive for unemployment. We thus feel 
confident that at least some of the geographical heterogeneity in labor market conditions is being captured by the inclusion of this variable. For both males and females, the estimated age effects are statistically significant determinants of employment but not of unemployment.

In both the OLS and IV results, schooling attainment is seen to have positive and significant relationships with employment for both males and females, although its negative relationships with unemployment are statistically significant only for males. With all else held constant, race is an important determinant of employment and unemployment for males with whites having higher employment and lower unemployment propensities than nonwhites. For females, race is not a significant determinant of employment propensity, but nonwhite females do have greater unemployment propensities than otherwise comparable white females.

For males, being married is a positive contributor to employment propensity but has little impact on unemployment. Given marital status, family size is not a significant determinant of either employment status outcome for males. Not unexpectedly, a very different picture emerges for females. Given family size, marital status is itself not a significant determinant of either employment or unemployment propensity. Family size, however, has a hugely significant negative impact on females' employment propensities and, interestingly, small but significant positive effects on unemployment propensities.

Increased levels of self-perceived healthiness are positively and significantly related to higher employment propensities for both males 
and females. Unemployment propensities, however, are less significantly related to health status, and in this instance higher levels of self-perceived healthiness correspond to lower unemployment propensities. The results for both males and females clearly suggest that poor health is a detriment to participation (either employed or unemployed) in the labor force.

\section{VII . SUMMEARY}

This paper has attempted to fill what we perceive to be a conspicuous gap in the literature on the economic aspects of problem drinking by estimating a set of structural employment status models that account for the possible endogeneity of problem drinking in such models. Since theory offers little guidance on appropriate exclusion restrictions, the econometric evidence presented here on how problem drinking causes employment problems must be weighed carefully in light of the reasonableness of the identifying restrictions invoked to estimate such models.

Our findings are consistent with the idea that problem drinking reduces employment and increases unemployment. The IV results produce point estimates of greater magnitude of these effects as compared to the oLS results, suggesting that for both men and women controlling for unobserved heterogeneity reveals a much bigger adverse impact of problem drinking on employment success. Interestingly, the conclusion that problem drinking results in reduced employment success tends to hold for females as well as males in the IV approach. This is in contrast to the conclusions that one would draw either looking 
only at the raw data from our sample or examining the oLs results for women.

When the instrumental variable approach is taken for our sample of women, the coefficients on problem drinking suggest a negative, although insignificant, impact on employment and a positive impact on unemployment. One interpretation of our findings is that the IV approach controls for some of the unobserved heterogeneity that is so important for women that, in raw data, the unobserved heterogeneity over-rides the underlying negative impact of problem drinking on employment. Due to this unobserved heterogeneity, the negative impact of problem drinking is not observed in raw data and, in fact, is generally not observed in OLS regressions either. Only when the IV approaches used is the underlying negative effect observed. This interpretation, we realize, is only one of the set of alternatives and rests on the belief that we have a decent set of instrumental

variables. Interestingly, the finding of a negative impact of problem drinking on employment confirms the results of a previous study of ours (Mullahy and Sindelar, 1991) that used a different data source to look at employment; we did not however, examine unemployment.

Our hope is that the strategy and results described here will point the way toward further research on these topics as new data are gathered. ${ }^{38}$ In particular, we look forward to research that uses structural estimation methods to describe how other labor market outcomes -- earnings, wages, labor supply, etc. -- are affected by problem drinking. In particular, we believe that future research 
should focus on how alcohol and problem drinking affect women's use of time in market versus home activities. Further, a focus on the interrelationships of alcohol with family structure, health and other possible pathways of indirect effects should be incorporated. As such research bears fruit, our understanding of the real costs of problem drinking will surely be sharpened.

Our future research agenda includes trying to estimate problem drinking as a function of unemployment using the IV approach. This analysis will complement our current approach of estimating unemployment as a function of problem drinking. We hypothesize further that unemployment insurance, and its degree of generosity, will mitigate to some extent the financial stress due to unemployment and thus will mitigate the extent to which unemployment causes problem drinking. Also, we would suggest that the appropriate alcohol variable would be increased consumption of alcohol or increased severity of symptoms of the symptoms of alcoholism, not alcoholism or even necessarily heavy drinking. Longitudinal data might be needed to analyze such increases in severity of symptoms and increases in consumption. These additional research efforts, however, are beyond the scope of this current paper. 
References

Amemiya, T. 1978. "The Estimation of a Simultaneous Equation

Generalized Probit Model". Econometrica 46: 1193-1205.

American Psychiatric Association. 1987. Diagnostic and statistical

Manual of Mental Disorders, Third Edition, Revised. Washington:

American Psychiatric Association.

Becker, G.S. 1974. "A Theory of Social Interactions". Journal of Political Economy 82: 1063-1091.

Benham, L. and A. Benham. 1982. "Employment, Earnings, and Psychiatric

Diagnosis." in V. Fuchs, ed Economic Aspects of Health. Chicago:

University of Chicago Press.

Berry, R. and Boland, J. The Economic Costs of Alcohol Abuse. New

York: Free Press, 1977.

Browning, M. and C. Meghir. 1991. "The Effects of Male and Female

Labor Supply on Commodity Demands." Econometrica 59: 925-951.

Cook, P.J. "The Social Costs of Drinking." in Expert Meeting on

Negative Social Consequences of Alcohol Use. Oslo: Norwegian

Ministry of Health and Social Affairs, 1991.

Cook, P.J. 1994. "Comments and Discussion on, Alcohol Consumption and

Young Adults' Socioeconomic Status", Brookings Papers on Economic

Activity: Microeconomics $162-166$

Cook, P.J and Moore, M.J. "Drinking and Schooling", Journal of Health Economics, 12:411-429, 1993 .

Deaton, A. and J. Muellbauer. 1980. Economics and Consumer Behavior.

Cambridge: Cambridge University Press.

Deaton, A., J. Ruiz-Castillo, and D. Thomas. 1989. "The Influence of Household Composition on Household Expenditure Patterns: Theory 
and Evidence." Journal of Political Economy 97: 179-200.

Forcier, M.W. "Labor Force Behavior of Alcoholics: A Review", The International Journal of Addiction, 20 (2):253-268, 1985.

French, M.T. and Zarkin, G.A. "Is Moderate Alcohol Use Related to Wages? Evidence from Four Worksites". Jounral of Health Economics, forthcoming.

Frezza, M., DePadova, C., Pozzato, G., Terpin, M., Baraona, E., Lieber, C.S. "High Blood Alcohol Levels in Women: The Role of Decreased Gastric Alcohol Dehydrogenase Activity and First-Pass Metabolism". New England Journal of Medicine, Vol. 322, No. $2: 95-99,1990$.

Gorman, D.M. Employment, "Stressful Life Events and the Development of Alcohol Dependence". Drug and Alcohol Dependence, 11:151-159, 1988.

Grant, B.F. et al. 1991. "Prevalence of DSM-III-R Alcohol Abuse and Dependence: United States, 1988." Alcohol Health \& Research World 15: $91-96$.

Grossman, M. 1972. "On the Concept of Health Capital and the Demand for Health." Journal of Political Economy 80: 223-255. Grossman, M. 1989. "Health Benefits of Increases in Alcohol and Cigarette Taxes." British Journal of Addiction 84: 1193-1204. Grossman, M., J. Sindelar, J. Mullahy, and R. Anderson. 1993. "Alcohol and Cigarette Taxes." Journal of Economic Perspectives 7: 211-222.

Hansen, L.P. 1982. "Large Sample Properties of Generalized Method of Moments Estimators." Econometrica 50: 1029-1054.

Hausman, J.A. and D.A. Wise. 1985. "Technical Problems in Social 
Experimentation: Cost versus Ease of Analysis" (with Comments by J. Conlisk and D.L. McFadden), in J.A. Hausman and D.A. Wise, eds. Social Experimentation. Chicago: University of Chicago Press for NBER.

Heckman, J. 1978. "Dummy Endogenous Variables in a Simultaneous Equations System." Econometrica 46: 931-961.

Heckman, J. and T.E. MaCurdy. 1985. "A Simultaneous Equations Linear Probability Model." Canadian Journal of Economics 18: 28-37.

Holland, P.W. 1986. "Statistics and Causal Inference." (also Comments and Rejoinder). JASA 81: 945-970.

Kenkel, D.S. and D.C. Ribar. 1994. "Alcohol Consumption and Young Adults' Socioeconomic status." Brookings Papers on Economic Activity: Microeconomics: 119-161.

Midanik, L.T. 1982. "The Validity of Self-reported Alcohol Consumption and Alcohol Problems: A Literature Review. British Journal of Addition $77: 357-382$.

Midanik, L.T. 1982. "Prespectives on the Validity of self-reported Alcohol Use" British Journal of Addition 84: 1419-1423, 1989. Moffitt, R. 1991. "Program Evaluation with Nonexperimental Data." Evaluation Review 15: 291-314.

Mullahy, J. 1993. "Alcohol and the Labor Market." in M. Hilton and G. Bloss, eds., Economics and the Prevention of Alcohol-Related Problems. Washington: National Institute on Alcohol Abuse and Alcoholism.

Mullahy, J. and W.G. Manning. 1994. "Statistical Issues in CostEffectiveness Analyses." in F. Sloan, ed. Valuing Health Care: Costs, Benefits, and Effectiveness of Pharmaceuticals and Other 
Medical Technologies. Cambridge: Cambridge University Press. Mullahy, J. and J.L. Sindelar. 1991. "Gender Differences in Labor Market Effects of Alcoholism." American Economic Review 81 (Papers and Proceedings): 161-165.

Mullahy, J. and J.L. Sindelar. 1993. "Alcoholism, Work, and Income." Journal of Labor Economics 11: 494-520.

Mullahy, J. and J.L. Sindelar. 1994. "Do Drinkers Know when to Say When? An Empirical Analysis of Drunk Driving." Economic Inquiry $32: 383-394$.

Mullahy, J. and Sindelar, J., 1994, "Alcoholism and Income: The Role of Indirect Effects". The Milbank Quarterly, 72:359-375.

Nelson, C.R. and R. Startz. 1990. "The Distribution of the Instrumental Variables Estimator and Its t-ratio when the Instrument Is a Poor One." Journal of Business 63: S125-S140. Phlips, L. 1983. Applied Consumption Analysis, Revised and Enlarged Edition. Amsterdam: North-Holland.

Pollak, R.A. and T.J. Wales. 1992. Demand System Specification and Estimation. New York: Oxford University Press. Rice, D.P., Kelman, S., Miller, L. S. and Dunmeyer, S. 1990. The Economic Costs of Alchohol and Drug Abuse and Mental Illness : 1985 DHHS Pub. No. (ADM) 90-1694. Washington, D.C. Supt. of Documents, U.S. Govt. Print. Off.

Roman, P.M. "Biological Features of Women's Alcohol Use: A Review". Public Health Reports, Vol. 103, No. 6:628-637, 1988 .

Rubin, D.B. 1974. "Estimating Causal Effects of Treatments in Randomized and Nonrandomized Studies." Journal of Educational Psychology 66: 688-701. 
Ruhm CJ. 1995. "Economic Conditions and Alcohol Problems" Journal of Heal th Economics, forthcoming.

Saffer, H. and M. Grossman. 1987. "Beer Taxes, the Legal Drinking Age, and Youth Motor Vehicle Fatalities." Journal of Legal Studies 16: $351-374$.

Sindelar, J. Measurement Issues in Alcohol Survey Data, NIAAA monograph, Economic Research on the Prevention of Alcohol Related Problems, Greg Bloss and Michael Hilton, editors, NIH Publication No. $93-3513$, pp. 201-228, 1993.

Sindelar, J. "The Effects of Alcoholism on Women's Labor Market Outcomes", forthcoming in Alcohol and Women: Prevention. NIAAA monograph.

Staiger, D. and J.H. Stock. 1993. "Asymptotics for Instrumental Variables Regressions with Weakly Correlated Instruments." Presented at the NBER Summer Institute, July 1993.

Steele, C.M. and R.A. Josephs. 1990. "Alcohol Myopia: Its Prized and Dangerous Effects." American Psychologist 45: 921-933.

Strauss, J. 1986. "Does Better Nutrition Raise Farm Productịity?" Journal of Political Economy $94: 297-320$.

Suen, W. and P.H. Mo. 1994. "Simple Analytics of Productive Consumption." Journal of Political Economy 102: 372-383.

U.S. Department of Health and Human Services, National Institute on Alcohol Abuse and Alcoholism. 1993. Eighth Special Report to the U.S. Congress on Alcohol and Health. Washington: NIH Publication No. $94-3699$.

White, H. 1982. "Instrumental Variables Regression with Independent Observations." Econometrica 50: 483-500. 
Wilsnack, R.W. and Wilsnack, S.C. "Women, Work, and Alcohol: Failures of Simple Theories". Alcoholism: Clinical and Experimental Research, Vol. 16, No. 2:172-179, 1992 .

World Health Organization. 1994. Lexicon of Alcohol and Drug Terms. Geneva: World Health Organization. 
Table 1

Variable Definitions

\section{Data from 1988 National Health Interview Survey}

EMPLOYED: 1 if employed in past two weeks, 0 else

UNEMPLOYED: 1 if participated in labor market, but not employed in past two weeks, 0 else

ETHANOL CONSUMPTION: Ethanol consumed in two-week period preceeding survey, in ounces of pure ethanol

ABUSE/DEPENDENCE: 1 if one-year (i.e. previous year) DSM-III-R alcohol abuse and/or alcohol dependence diagnosed, 0 else

90TH PERCENTILE HEAVY DRINKING: 1 if individual exceeds sample 90th percentile of ethanol consumption ( $18.0 \mathrm{oz}$. for males, $5.8 \mathrm{oz}$. for females), 0 else

95TH PERCENTILE HEAVY DRINKING: 1 if individual exceeds sample 95 th percentile of ethanol consumption (28.8 oz. for males, $10.8 \mathrm{oz}$. for females), 0 else

AGE : Age in Years

SCHOOLING: Years of completed schooling

FAMILY SIZE: Size of family

WHITE: 1 if white, 0 else

MARRIED: 1 if married, 0 else

EXCELLENT: 1 if health status reported excellent, 0 else

VERY GOOD: 1 if health status reported very good, 0 else

GOOD: 1 if health status reported good, 0 else

FAIR: 1 if health status reported fair, 0 else

NORTHEAST: 1 if resides in northeast region of U.S., 0 else

MIDWEST: 1 if resides in midwest region of U.S., 0 else

SOUTH: 1 if resides in south region of U.S., 0 else

CENTER CITY: 1 if resides in MSA, central city, 0 else

OTHER MSA: 1 if resides in MSA, not central city, 0 else

LIVED WITH ALCOHOLIC: 1 if lived with a problem drinker/alcoholic during first 18 years, 0 else

BIOLOGICAL MOTHER ALCOHOLIC: 1 if biological mother is/was problem drinker, 0 else

BIOLOGICAL FATHER ALCOHOLIC: 1 if biological father is/was problem drinker, 0 else

(continued) 
(Table 1, continued)

Supplementary state-Level Data Matched to 1988 NHIS

UE88: State unemployment rate (Source: statistical Abstract of the U.S.).

BEER TAX: State beer excise tax rate, in dollars (Source: Brewer's Almanac, 1989).

APPARENT ETHANOL: Apparent ethanol consumption, per capita (Source: Brewer's Almanac, 1989).

CIGARETTE TAX: state cigarette excise tax rate, in cents (Source: The Tax Burden on Tobacco, 1989).

Q1, Q2, and Q3: Quarters in which the survey was conducted, the omitted category is the fourth quarter. 
Table 2

Sample Descriptive Statistics

\begin{tabular}{|c|c|c|c|c|c|c|c|c|}
\hline \multirow[b]{2}{*}{ Variable } & \multicolumn{4}{|c|}{ Males } & \multicolumn{4}{|c|}{ Females } \\
\hline & Obs. & Mean & Min & $\operatorname{Max}$ & Obs. & Mean & $\operatorname{Min}$ & $\operatorname{Max}$ \\
\hline EMPLOYED & 10421 & 0.90 & 0.0 & 1.0 & 13384 & 0.70 & 0.0 & 1.0 \\
\hline UNEMPLOYED & 10421 & 0.03 & 0.0 & 1.0 & 13384 & 0.04 & 0.0 & 1.0 \\
\hline ETHANOL CONSUMPTION & 9822 & 8.32 & 0.0 & 8467.2 & 12534 & 2.30 & 0.0 & 512.4 \\
\hline ABUSE/DEPENDENCE & 10421 & 0.15 & 0.0 & 1.0 & 13384 & 0.05 & 0.0 & 1.0 \\
\hline 90TH PCTL. HVY. DKG. & 9822 & 0.10 & 0.0 & 1.0 & 12534 & 0.10 & 0.0 & 1.0 \\
\hline 95TH PCTL. HVY. DKG. & 9822 & 0.05 & 0.0 & 1.0 & 12534 & 0.05 & 0.0 & 1.0 \\
\hline UE8 8 & 10421 & 5.56 & 2.8 & 10.9 & 13384 & 5.59 & 2.8 & 10.9 \\
\hline AGE & 10421 & 39.21 & 25.0 & 59.0 & 13384 & 38.85 & 25.0 & 59.0 \\
\hline SCHOOLING & 10421 & 13.30 & 0.0 & 19.0 & 13384 & 12.90 & 0.0 & 19.0 \\
\hline MARRIED & 10421 & 0.81 & 0.0 & 1.0 & 13384 & 0.86 & 0.0 & 1.0 \\
\hline FAMILY SIZE & 10421 & 2.73 & 1.0 & 13.0 & 13384 & 2.92 & 1.0 & 15.0 \\
\hline WHITE & 10421 & 0.85 & 0.0 & 1.0 & 13384 & 0.80 & 0.0 & 1.0 \\
\hline EXCELLENT & 10421 & 0.41 & 0.0 & 1.0 & 13384 & 0.35 & 0.0 & 1.0 \\
\hline VERY GOOD & 10421 & 0.30 & 0.0 & 1.0 & 13384 & 0.30 & 0.0 & 1.0 \\
\hline GOOD & 10421 & 0.21 & 0.0 & 1.0 & 13384 & 0.25 & 0.0 & 1.0 \\
\hline FAIR & 10421 & 0.05 & 0.0 & 1.0 & 13384 & 0.08 & 0.0 & 1.0 \\
\hline NORTHEAST & 10421 & 0.20 & 0.0 & 1.0 & 13384 & 0.19 & 0.0 & 1.0 \\
\hline MIDWEST & 10421 & 0.26 & 0.0 & 1.0 & 13384 & 0.26 & 0.0 & 1.0 \\
\hline SOUTH & 10421 & 0.32 & 0.0 & 1.0 & 13384 & 0.33 & 0.0 & 1.0 \\
\hline CENTER CITY & 10421 & 0.34 & 0.0 & 1.0 & 13384 & 0.35 & 0.0 & 1.0 \\
\hline OTHER MSA & 10421 & 0.43 & 0.0 & 1.0 & 13384 & 0.42 & 0.0 & 1.0 \\
\hline BEER TAX & 10421 & 0.42 & 0.1 & 2.4 & 13384 & 0.44 & 0.1 & 2.4 \\
\hline APPARENT ETHANOL & 10421 & 2.04 & 1.0 & 4.0 & 13384 & 2.03 & 1.0 & 4.0 \\
\hline CIGARETTE TAX & 10421 & 17.88 & 2.0 & 38.0 & 13384 & 17.71 & 2.0 & 38.0 \\
\hline LIVED WITH ALCOHOLIC & 10421 & 0.19 & 0.0 & 1.0 & 13384 & 0.23 & 0.0 & 1.0 \\
\hline BIOL. MOTHER ALC. & 10421 & 0.04 & 0.0 & 1.0 & 13384 & 0.06 & 0.0 & 1.0 \\
\hline BIOL. FATHER ALC. & 10421 & 0.15 & 0.0 & 1.0 & 13384 & 0.19 & 0.0 & 1.0 \\
\hline
\end{tabular}


Table 3

Sample Means of Employment status by problem Drinking status ("No PD" vs. "PD") for ABUSE/DEPENDENCE and 90TH AND 95TH PERCENTILE HEAVY DRINKING

( $t$-stats. for differences in parentheses)

\begin{tabular}{|c|c|c|c|c|c|c|c|c|}
\hline & \multicolumn{4}{|c|}{ MALES } & \multicolumn{4}{|c|}{ FEMALES } \\
\hline & \multicolumn{2}{|c|}{ EMPLOYED } & \multicolumn{2}{|c|}{ UNEMPLOYED } & \multicolumn{2}{|c|}{ EMPLOYED } & \multicolumn{2}{|c|}{ UNEMPLOYED } \\
\hline & No $P D$ & PD & No $\mathrm{PD}$ & PD & No $P D$ & PD & No $P D$ & PD \\
\hline ABUSE/DEPEND. & .901 & .876 & $.030_{13}$ & .052 & .696 & .739 & .034 & .066 \\
\hline $\begin{array}{l}\text { 90TH PCTL. } \\
\text { HEAVY DKG. }\end{array}$ & .901 & .872 & .031 (1 & .042 & .686 & .749 & .034 & .045 \\
\hline $\begin{array}{l}\text { 95TH PCTL. } \\
\text { HEAVY DKG. }\end{array}$ & .901 & .849 & .031 & .052 & .690 & .738 & .035 & .048 \\
\hline
\end{tabular}


Table 4

Summary of Alcohol Parameter Point Estimates (t-stats.)

\begin{tabular}{|c|c|c|c|c|c|c|c|c|c|c|}
\hline & \multicolumn{5}{|c|}{ MALES } & \multicolumn{5}{|c|}{ FEMALES } \\
\hline & \multicolumn{2}{|c|}{ EMPLOYMENT } & \multicolumn{2}{|c|}{ UNEMPLOYMENT } & \multirow{2}{*}{$\begin{array}{c}\text { OVERID. } \\
\text { TEST } \\
(p-v a l)\end{array}$} & \multicolumn{2}{|c|}{ EMPLOYMENT } & \multicolumn{2}{|c|}{ UNEMPLOYMENT } & \multirow{2}{*}{$\begin{array}{c}\text { OVERID. } \\
\text { TEST } \\
\text { (p-val) }\end{array}$} \\
\hline & OLS & IV & OLS & IV & & OLS & IV & OLS & IV & \\
\hline $\begin{array}{l}\text { ABUSE/ } \\
\text { DEPENDENCE }\end{array}$ & $\begin{array}{l}-.021 \\
(2.5)\end{array}$ & $\begin{array}{l}-.131 \\
(1.6)\end{array}$ & $\begin{array}{r}.019 \\
(3.2)\end{array}$ & $\begin{array}{l}.062 \\
(1.2)\end{array}$ & $\begin{array}{l}26.6 \\
(.047)\end{array}$ & $(0.014$ & $\begin{array}{c}-.153 \\
(0.9)\end{array}$ & $\begin{array}{l}.029 \\
(3.0)\end{array}$ & $\begin{array}{r}.103 \\
(1.3)\end{array}$ & $\begin{array}{l}26.1 \\
(.053)\end{array}$ \\
\hline $\begin{array}{l}\text { 90TH PCTL. } \\
\text { HEAVY DKG }\end{array}$ & $\begin{array}{r}-.016 \\
(1.5)\end{array}$ & $\begin{array}{l}-.147 \\
(1.2)\end{array}$ & $\begin{array}{r}.010 \\
(1.5)\end{array}$ & $\begin{array}{l}.069 \\
(0.9)\end{array}$ & $\begin{array}{l}25.8 \\
(.057)\end{array}$ & $\begin{array}{l}.006 \\
(0.5)\end{array}$ & $\begin{array}{l}-.127 \\
(0.8)\end{array}$ & $\begin{array}{r}.015 \\
(2.5)\end{array}$ & $\begin{array}{r}.035 \\
(0.5)\end{array}$ & $\begin{array}{l}22.6 \\
(.124)\end{array}$ \\
\hline $\begin{array}{l}\text { 95TH PCTL. } \\
\text { HEAVY DKG }\end{array}$ & $\begin{array}{l}-.021 \\
(1.4)\end{array}$ & $\begin{array}{l}-.332 \\
(1.5)\end{array}$ & $\begin{array}{l}.019 \\
(1.8)\end{array}$ & $\begin{array}{l}.190 \\
(1.4)\end{array}$ & $\begin{array}{l}24.1 \\
(.088)\end{array}$ & $\begin{array}{l}-.010 \\
(0.6)\end{array}$ & $\begin{array}{l}-.256 \\
(0.9)\end{array}$ & $\begin{array}{l}.017 \\
(2.0)\end{array}$ & $\begin{array}{l}.142 \\
(1.1)\end{array}$ & $\begin{array}{l}21.6 \\
(.157)\end{array}$ \\
\hline $\begin{array}{l}\text { ETHANOL } \\
\text { CONSUMPTION }\end{array}$ & $\begin{array}{c}3.8 E-6 \\
(0.2)\end{array}$ & $\begin{array}{l}.0002 \\
(0.3)\end{array}$ & $\begin{array}{c}4.4 E-6 \\
(0.5)\end{array}$ & $\begin{array}{r}-9.9 E-6 \\
(0.3)\end{array}$ & $\begin{array}{l}27.7 \\
(.034)\end{array}$ & $\begin{array}{l}.0002 \\
(0.5)\end{array}$ & $\begin{array}{l}-.006 \\
(0.7)\end{array}$ & $\begin{array}{l}.0004 \\
(1.5)\end{array}$ & $\begin{array}{l}.003 \\
(0.9)\end{array}$ & $\begin{array}{l}22.3 \\
(.134)\end{array}$ \\
\hline
\end{tabular}




\section{APPENDIX Table A1}

OLS and IV Full Results: Males, All Ages, 90TH PERCENTILE HEAVY DRINKING Alcohol Measure (Asymptotic t-statistics in parentheses)

EMPLOYMENT

Variable
UNEMPLOYMENT

OLS

\begin{tabular}{|c|c|c|c|c|c|c|c|c|}
\hline $\begin{array}{l}90 T H \text { PCTL. HVY. DKG. } \\
\text { UE8 } 8 \\
\text { AGE }_{2} \\
\text { AGE } \\
\text { SCHOOLING } \\
\text { MARRIED } \\
\text { FAMILY SIZE } \\
\text { WHITE } \\
\text { EXCELLENT } \\
\text { VERY GOOD } \\
\text { GOOD } \\
\text { FAIR } \\
\text { NORTHEAST } \\
\text { MIDWEST } \\
\text { SOUTH } \\
\text { CENTER CITY } \\
\text { OTHER MSA } \\
\text { Q1 } \\
\text { Q2 } \\
\text { Q3 } \\
\text { CONSTANT }\end{array}$ & $\begin{array}{r}-0.016 \\
-0.009 \\
0.016 \\
-.0002 \\
0.008 \\
0.077 \\
0.002 \\
0.051 \\
0.575 \\
0.573 \\
0.538 \\
0.395 \\
-0.001 \\
0.005 \\
0.025 \\
-0.016 \\
0.007 \\
-0.016 \\
-0.007 \\
-0.004 \\
-0.096\end{array}$ & $\begin{array}{l}(1.524) \\
(4.047) \\
(5.568) \\
(5.989) \\
(6.951) \\
(7.423) \\
(0.947) \\
(5.145) \\
(18.78) \\
(18.71) \\
(17.43) \\
(11.15) \\
(0.145) \\
(0.600) \\
(3.105) \\
(1.910) \\
(1.011) \\
(1.965) \\
(0.887) \\
(0.458) \\
(1.539)\end{array}$ & $\begin{array}{r}-0.147 \\
-0.010 \\
0.016 \\
-.0002 \\
0.007 \\
0.079 \\
0.000 \\
0.048 \\
0.573 \\
0.574 \\
0.540 \\
0.400 \\
-0.004 \\
0.003 \\
0.023 \\
-0.015 \\
0.007 \\
-0.014 \\
-0.007 \\
-0.004 \\
-0.059\end{array}$ & $\begin{array}{l}(1.201) \\
(4.477) \\
(5.379) \\
(5.794) \\
(5.889) \\
(7.250) \\
(0.168) \\
(4.808) \\
(18.69) \\
(18.86) \\
(17.62) \\
(11.32) \\
(0.386) \\
(0.308) \\
(2.807) \\
(1.674) \\
(0.967) \\
(1.710) \\
(0.907) \\
(0.458) \\
(0.943)\end{array}$ & $\begin{array}{r}0.010 \\
0.005 \\
-0.001 \\
.00001 \\
-0.003 \\
-0.025 \\
0.000 \\
-0.009 \\
0.015 \\
0.018 \\
0.023 \\
0.018 \\
0.001 \\
-0.003 \\
-0.007 \\
-0.001 \\
-0.006 \\
0.015 \\
0.002 \\
0.000 \\
0.093\end{array}$ & $\begin{array}{l}(1.499) \\
(3.074) \\
(0.854) \\
(0.597) \\
(4.467) \\
(3.884) \\
(0.282) \\
(1.545) \\
(1.319) \\
(1.560) \\
(1.934) \\
(1.314) \\
(0.135) \\
(0.543) \\
(1.277) \\
(0.169) \\
(1.171) \\
(2.806) \\
(0.480) \\
(0.009) \\
(2.547)\end{array}$ & $\begin{array}{r}0.069 \\
0.005 \\
-0.002 \\
.00002 \\
-0.003 \\
-0.027 \\
0.001 \\
-0.008 \\
0.016 \\
0.018 \\
0.022 \\
0.015 \\
0.001 \\
-0.002 \\
-0.006 \\
-0.001 \\
-0.005 \\
0.014 \\
0.003 \\
0.002 \\
0.085\end{array}$ & $\begin{array}{l}(0.896) \\
(3.198) \\
(0.990) \\
(0.772) \\
(3.589) \\
(4.120) \\
(0.584) \\
(1.375) \\
(1.400) \\
(1.539) \\
(1.886) \\
(1.139) \\
(0.178) \\
(0.340) \\
(1.185) \\
(0.195) \\
(1.074) \\
(2.780) \\
(0.658) \\
(0.350) \\
(2.324)\end{array}$ \\
\hline
\end{tabular}




\section{APPENDIX Table A2}

OLS and IV Full Results: Females, All Ages, 90TH PERCENTILE HEAVY DRINKING Alcohol Measure (Asymptotic t-statistics in parentheses)

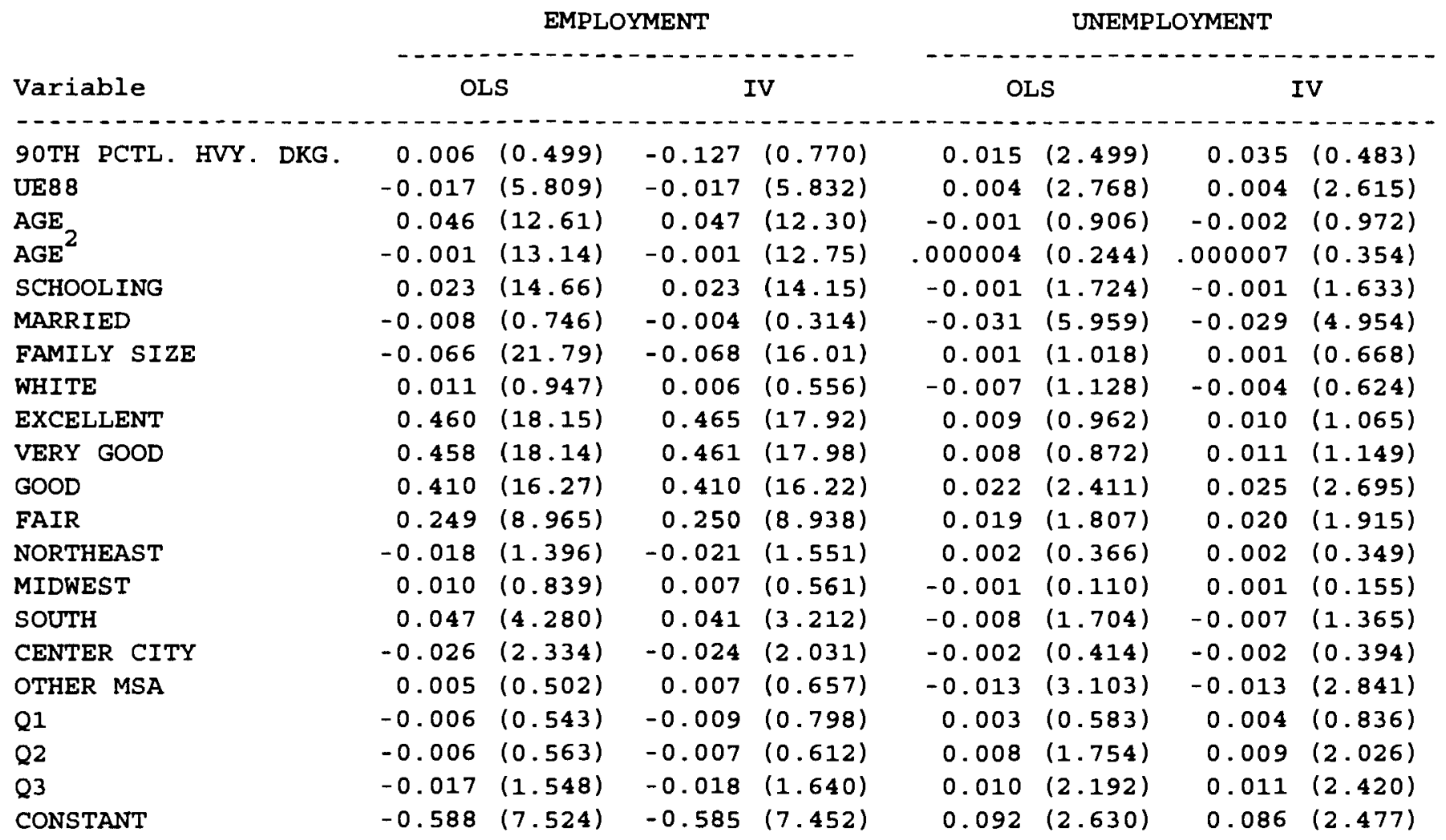

